\title{
The Racialized Impact of Study Abroad on US Students' Subsequent Interracial Interactions
}

\author{
Maria R. Lowe, ${ }^{1}$ Reginald A. Byron, ${ }^{1}$ and Susan Mennicke ${ }^{2}$ \\ ${ }^{1}$ Department of Sociology and Anthropology, Southwestern University, 1001 E. University Avenue, Georgetown, TX 78626, USA \\ ${ }^{2}$ International Programs, Franklin and Marshall College, P.O. Box 3003, Lancaster, PA 17604, USA \\ Correspondence should be addressed to Maria R. Lowe; lowem@southwestern.edu
}

Received 20 August 2014; Accepted 10 November 2014; Published 1 December 2014

Academic Editor: Bernhard Schmidt-Hertha

Copyright (c) 2014 Maria R. Lowe et al. This is an open access article distributed under the Creative Commons Attribution License, which permits unrestricted use, distribution, and reproduction in any medium, provided the original work is properly cited.

\begin{abstract}
Using an online survey of American undergraduate students, this paper serves as a case study of a liberal arts college located in the Southern United States (US) to explore the effects of studying abroad on students' attitudes and behavior related to diversity upon their return to campus. We find that white students and students of color report significantly different study abroad experiences and distinct patterns related to their likelihood to engage with racial, but not other forms of, diversity when they return to their home university. Specifically, students of color are more likely than white students to report that their study abroad experiences have increased the likelihood that they interact more frequently with individuals from different racial backgrounds in a number of campus contexts. Utilizing existing literature and our qualitative data, we address possible reasons for these racialized patterns.
\end{abstract}

\section{Introduction}

At the 2012 Association of International Education Administrators annual conference, experts in the field of education abroad discussed the challenges associated with increasing diversity in study abroad participation among students who attend colleges and universities in the United States [1]. Whereas study abroad participation has grown significantly among American undergraduate students in general over recent decades, there are still specific groups that are notably underrepresented, including students of color (note: we use the terms students of color and racial and ethnic minorities interchangeably to denote African American, Asian American, Latino/a, and Native American students) $[1,2]$. In 2011 , the US undergraduate population consisted of $32 \%$ students of color at private universities and $37 \%$ at public institutions [3]. However, they represented only $22 \%$ of students who studied abroad outside the United States [4]. For many educators, this discrepancy is troubling and should serve as a motivating force for American universities to find constructive ways to diversify study abroad participation $[1,5]$. Understanding how race is related to students' study abroad experiences and their views upon their return to their home institution would help to facilitate this goal.
Recent research calls into question any prior speculation that white students and students of color in the US intend to or ultimately participate in study abroad because of the same human, financial, institutional, and cultural capital factors $[2,5,6]$. It may similarly be the case that there are racialized patterns in the experiences and outcomes of education abroad for American students. Yet, while some studies have noted that students of color benefit from study abroad experiences (see [7]), little is presently known about the racialized experiences of students while abroad and when they return to their universities. Using a mixed methods approach, the current paper serves as a case study and explores whether students of color and white students attending a university in the Southern United States have similar experiences when studying abroad and whether these experiences, in turn, affect their attitudes and behaviors related to diversity, particularly racial diversity, when they return to their home campus.

Background. Although extensive research on education abroad, curriculum integration, and the internationalization of higher education has been conducted by scholars around the world, few studies have been conducted by researchers outside the US on the intersection of race and education 
abroad. This dearth of scholarship is likely due to the fact that the term "race" is rarely utilized outside of North America. Consequently, the use of race as a category of inquiry may be unique to the United States. Even so, because student engagement in international higher education is on the rise globally and interaction with intellectual and cultural difference is among the prime motivators for this increasingly internationalized approach among universities around the world, the current study may be of interest to scholars both within and outside the United States.

Much of the literature that examines the effects of studying abroad on US students' openness to diversity focuses on issues such as intercultural and international diversity. Indeed, the field has occupied itself with basic questions and assumptions about the efficacy of study abroad in fostering positive developmental goals in student participants [8]. Research has also explored the effects of study abroad on American students' engagement with world events and their development of marketable skills [9]. Students have a more sustained interest in world news and affairs as a result of studying abroad $[10,11]$. Likewise, students who study abroad are more likely to develop enhanced critical thinking and problem solving skills than other students $[12,13]$.

Within the last decade, the field of education abroad has been challenged to clarify desired outcomes, to produce reliable assessment strategies, and to discern appropriate methods to effectively test for stated goals $[14,15]$. Impressive work has been conducted and practitioners in the field now have access to sophisticated conceptualizations of a variety of outcomes for study abroad [16]. Likewise, educational and pedagogical goals in study abroad programming have in general become more thoughtful and holistic [17-19]. No longer is the belief held that study abroad will always, and by definition, produce positive learning outcomes [20, 21]. Rather, in focusing on particular outcomes, the assessment of study abroad has simply become better, while involving increased expectations of student participants [22, 23]. Thus, while goals of intercultural competence, global awareness, and openness to difference are all still among the traits and skills we hope that students develop, the field has created a much more articulated notion of what is meant by those terms and goals [24].

Still, very little work has examined the effect of study abroad on student engagement with racial diversity specifically. Instead, the existing research on the US tends to focus on "openness to diversity" which has been defined by Chickering and Reisser [25] as a "broadening of awareness and experience [that] leads to an appreciation of cultural diversity and a comfort with people from all walks of life" [26]. Pascarella et al. [27] have developed an "openness to diversity/challenge" scale. Using this scale, Wortman [26] and others (e.g., [28]) find that students who study abroad stated being more open to diversity in general as a result of their study abroad experiences. Those students who were fully integrated into their host culture and who studied abroad in English-speaking countries particularly reported increases in openness to diversity. Unfortunately, attitudes, openness, and behaviors pertaining to racial diversity are rarely explicitly assessed (for an exception see [20]).
However, if one considers the abundance of research that shows how race profoundly affects US college students' attitudes and behaviors toward diverse others [29-35], there is reason to believe that race will play an important role in shaping the study abroad experience and psychosocial outcomes among students. With this foundation, the current mixed methods exploratory case study of a liberal arts college adds to the growing body of work on returnees' reported experiences after studying abroad (see [36]).

\section{Data and Methods}

It is worth noting that our study focuses exclusively on US students who study abroad and thus our discussion centers solely on outcomes associated with education abroad in the context of US-based higher education. Data for our analysis come from an online survey with both closedended and open-ended questions. The respondents were American undergraduate students at a small fairly selective predominantly white liberal arts institution located in the Southern United States. Approximately $90 \%$ of the university faculty and $75 \%$ of the students identify as white. Roughly half of the students study abroad during their time at the university with most participating in semester-long programs in Europe (roughly split between English and non-English native language countries) and about 30\% enrolling in summer study abroad experiences.

We administered an online survey in the spring of 2011. In March, returning study abroad students were contacted via email by the Office of Intercultural Learning to participate in an online survey on the relationship between their study abroad participation and their attitudes and experiences towards difference. The survey included approximately 65 closed-ended questions. The selected questions were guided by themes in the literature. For example, we incorporated a revised version of Pascarella et al.s [27] openness to diversity scale. In addition, we included questions about reported willingness to engage more or less frequently with people from different backgrounds along five dimensions: religious, racial, and cultural experiences, different countries, and political beliefs. For each of these dimensions, we asked a set of four questions. There were eight additional questions that focused on the frequency of interracial interactions in a variety of campus settings. We also included four questions asking about students' level of campus involvement and degree of commitment to enhancing diversity at the university as a result of studying abroad. Finally, the online survey also consisted of six open-ended survey questions which focused on students' reflections on how studying abroad affected their openness to diversity on campus.

Of the slightly over 200 returning study abroad students who were on campus in spring 2011, 102 initiated taking the survey and 62 completed it, which yields a response rate of slightly more than $30 \%$. This attrition can, in part, be explained by the survey's length and its perceived sensitive nature-which caused some respondents not to complete it. As one respondent noted in an open-ended response, "The racialized aspect of this survey is weird and awkward. 
TABle 1: Comparative demographic data: students who studied abroad, 2010-2011.

\begin{tabular}{lccc}
\hline & National (IIE data) & University & Sample \\
\hline Students of color & $22 \%$ & $20 \%$ & $11 \%$ \\
White students & $78 \%$ & $80 \%$ & $89 \%$
\end{tabular}

Source for national data: [4].

I am hostile to the implications of this survey." Although the completed response rate of $30 \%$ can be viewed as low, it is in line with those of other surveys examining race on American university campuses (see [37]). Particularly given the focus of the survey (the effect of study abroad on engagement with diversity among students in the American South), the response rate is arguably acceptable.

As Table 1 indicates, the sample is less racially diverse than both the university's study abroad population and the study abroad population nationally $[4,38]$. Given the small proportion of Blacks, Latinos, Asian Americans, and Native Americans in the sample (sample size $=7$ ), we decided to aggregate all of the students of color into one group. The remainder of the respondents (sample size $=55$ ) consisted of White (non-Latino) students. Although this aggregation is less than ideal, it is a strategy employed in other study abroad research (e.g., [20]). Also, women represented the majority of respondents $(79 \%)$ (see Table 2 for additional demographic information). Finally, the majority of respondents participated in a semester-long study abroad program with the most common destinations being Europe and Latin America.

2.1. Analytic Strategy. Our analysis relies on a mixed methods approach. Using both quantitative and qualitative data analyses allows us to connect statistical patterns with students' own reports of their study abroad experiences and how these experiences affect their attitudes and behaviors regarding different forms of diversity. Because our sample size is so small, we could not conduct predictive analyses. Therefore, we used Mann-Whitney $U$ tests for most of our analyses and, in two cases, we used a chi-square test because of the shape of the dependent variables (i.e., students were in a homestay situation or not and students taking courses in a language other than English or not). We chose the MannWhitney $U$ test because it is the nonparametric test that should be used when the dependent variables are ordinal scales and parametric assumptions are not met [39]. We initially ran Student's $t$-tests on these data. Although $t$-tests are commonly used and the variables presented here are similarly significant with Student's $t$-test analyses, because these preliminary analyses revealed violations of Student's $t$ test's homogeneity of variance assumption we chose to rely on Mann-Whitney $U$ statistics as the more suitable option. The Mann-Whitney $U$ test measures whether the two group medians are equal, but we also provide the mean and standard deviation in our tables to provide the reader with further information about central tendency.

We supplement the quantitative information with qualitative survey responses. Relying in part on the thematic analysis model discussed by Braun and Clarke [40], we engaged in
TABLE 2: Additional demographic data.

\begin{tabular}{lc}
\hline Category (sample size = 62) & Percentage \\
\hline Academic stage during study abroad & - \\
$\quad$ First-year & $13 \%$ \\
Sophomore & $76 \%$ \\
Junior & $11 \%$ \\
$\quad$ Senior & \\
Study abroad semester & $42 \%$ \\
$\quad$ Fall & $30 \%$ \\
Spring & $28 \%$ \\
$\quad$ Summer & \\
Study abroad program length & $39 \%$ \\
$\quad$ Less than four months & $40 \%$ \\
Four months & $20 \%$ \\
Four to six months & \\
Living situation during study abroad & $44 \%$ \\
Homestay & $54 \%$ \\
Apartment or residence hall with others & $2 \%$ \\
Single apartment & \\
Language spoken in courses & \\
Courses in English in an English speaking country & $40 \%$ \\
Courses in English in a non-English speaking & $21 \%$ \\
country & \\
Courses in a foreign language & $39 \%$ \\
\hline
\end{tabular}

a thorough and rigorous analysis of the qualitative data. As part of the process of qualitative analysis, the authors carefully read through the responses to the open-ended questions. We then discussed the themes we each found within and across racial groups, identified common patterns, compared these data to the quantitative findings, and placed applicable qualitative data into themes that matched the quantitative patterns. Following this process, we included relevant quotes to highlight, and provide context for, the quantitative themes. Finally, we integrated our findings with existing pertinent literature.

\section{Results}

We examined seven demographic and program variables including gender, race, economic class, length of stay, type of program, academic stage (first year, sophomore, etc.), and major. For each of these variables, we used Mann-Whitney $U$ tests to compare the medians between groups of students relative to the forty-eight experiential, attitudinal, and reported willingness-to-engage-with-diversity variables. Of the seven demographic and program variables, race was by far the most meaningful. That is, there was a statistically significant difference between white respondents and respondents of color for nineteen of the forty-eight experiential, attitudinal, and reported willingness-to-engage-with-diversity variables. The other six demographic and program variables each had three or fewer (out of forty-eight) statistically significant 
TABLE 3: Mean and Mann-Whitney $U$ test results (as a result of studying abroad...).

\begin{tabular}{lccc}
\hline Survey question & $\begin{array}{c}\text { Mean for students of color } \\
\text { (standard deviation) }\end{array}$ & $\begin{array}{c}\text { Mean for white students } \\
\text { (standard deviation) }\end{array}$ & $U(\mathrm{df})=u$ value, $Z=z$ value, $P$ value \\
\hline $\begin{array}{l}\text { More frequent interracial interactions } \\
\text { at campus social gatherings }\end{array}$ & $4.00(.816)$ & $3.41(.567)$ & $U(59)=109.0, Z=-2.085, P=.037$ \\
$\begin{array}{l}\text { More frequent interracial interactions } \\
\text { at off-campus gatherings }\end{array}$ & $4.00(.817)$ & $3.39(.627)$ & $U(59)=106.5, Z=-2.200, P=.028$ \\
$\begin{array}{l}\text { More frequent interracial on campus } \\
\text { generally }\end{array}$ & $5.43(1.51)$ & $3.98(1.35)$ & $U(60)=92.0, Z=-2.292, P=.022$ \\
$\begin{array}{l}\text { Seek out a greater diversity of friends } \\
\text { based on race on campus } \\
\begin{array}{l}\text { More likely to join diversity-related } \\
\text { student organizations/groups }\end{array}\end{array}$ & $5.29(1.25)$ & $4.00(1.32)$ & $U(60)=100.5, Z=-2.099, P=.036$ \\
\hline
\end{tabular}

Note: $\mathrm{df}$ stands for degrees of freedom. A response scale of 1 (much less likely) to 5 (much more likely) was used for the first two variables and the last variable presented here. A response scale of 1 (strongly disagree) to 7 (strongly agree) was used for the remaining two variables.

differences on the attitudinal and behavioral variables of interest.

Table 3 includes the Mann-Whitney $U$ tests results for five of the nineteen statistically significant variables. These variables focus on the perceived impact of study abroad on respondents' behavior regarding racial diversity once they had returned to campus. As the findings indicate, there is a statistically significant difference between students of color and white students for all five variables such that students of color are more likely than white students to report that studying abroad has had an effect on their willingness to engage with racial diversity on campus. While these quantitative findings are extremely compelling, we still do not have a clear understanding of why they exist.

We turn to our qualitative results for potential explanations. We place our findings into three categories: reported positive, neutral, and negative effects of study abroad on subsequent interracial interaction. Here, we code positive effects as stated increases in the frequency in which respondents engage with racial diversity. A neutral effect is one where the student reports no change in their engagement with racially dissimilar others and a negative impact is one where respondents reveal that study abroad has actually led to a decrease in the frequency in which they interact with members of different racial groups. In general, we find that while a large percentage of white students and students of color credit study abroad with having a positive effect on their interactions with racial diversity, students of color are more likely than white students to state that study abroad has had such a positive effect. In addition, white students are more likely than students of color to state that study abroad has had no effect on the frequency with which they engage with other racial groups. Finally, a small number of white students and none of the students of color disclose that study abroad has had a negative impact on the frequency with which they engage with racial diversity.

3.1. Positive Effects. Students of color are more likely than white students to report that as a result of their study abroad experiences, they interact more frequently with people from different racial backgrounds on campus generally as well as in particular settings. In fact, $50 \%$ of students of color compared to $26 \%$ of white students state that studying abroad positively affected the ways in which they interact with people from different racial backgrounds. Interestingly, in their descriptions, white students are more likely to mention their increased willingness to initially interact with people from different racial backgrounds.

Some students of color express similar sentiments as those conveyed by white respondents. For instance, one student of color explains that as a result of studying abroad, they are now "more inclined to make an effort with people in general regardless of race." However, others present a slightly more nuanced response. They talk more about the ways study abroad has enhanced their ongoing understanding of others or strengthened their interests in interactions across racial groups. One student of color reports, "I engage with people differently-I am better able to understand where others come from, which has enabled me to make more friends." The quantitative findings support these sentiments. Specifically, there is a statistically significant difference between students of color and that of white students such that students of color are more likely to say that as a result of studying abroad, they seek out a greater diversity of friends based on race. More so for students of color than white students, this enhanced understanding also leads to a reported increase in more enduring types of interactions.

While both white students and students of color suggest that their study abroad experiences have affected their openness to racial diversity on campus, students of color (67\%) are more likely than their white counterparts (36\%) to express such an effect. Once again, there is a subtle difference in the responses of white students and students of color. White students are more likely to explain that study abroad has actually made them aware or piqued their interest in racial diversity for the first time. For example, one white woman states, "I now see racial diversity is much more important than I ever thought before." Students of color, instead, talk about how study abroad has reinforced a preexisting interest. For instance, one student of color explains, "study abroad has only strengthened my openness to racial diversity on campus." 
Another notable finding is that students of color are more likely than their white counterparts to report that their increased openness to racial diversity translates into seeing their university differently. In fact, there are statistically significant differences between students of color and white students for being more likely to join a diversity-related student organization/group and to engage in more frequent interracial interactions on campus.

3.2. Neutral Effects. Half of the students of color and nearly two-thirds of the white students report that their study abroad experiences did not alter their likelihood of interacting with people from different racial backgrounds. For instance, a white student reports: "Honestly, not really.....I interact with people from different racial backgrounds the same as I did before the study abroad experience." Another white student explains: "No, I have always been comfortable interacting with people from different racial backgrounds." A student of color explains, "I am Mexican American and I attract friends from different racial backgrounds from German, Nigerian, to other Hispanics. Study abroad gave me an enjoyable experience culturally but my racial diversity [engagement] continues to be strong."

Furthermore, 33\% of students of color and $64 \%$ of white students report that studying abroad has not affected their openness to racial diversity on campus. For both white students and students of color in this category, the majority preface their comments with a qualifier about how they have always been open to racial diversity. For instance, a sizeable number of white students explain, "I have always been open to racial diversity on campus. Study abroad did not really change it." Likewise, a student of color states, "My racial diversity within my friends has stayed consistent and strong. I have always been intensely interested in different cultures and I continue to have the same passion." Particularly given the work of Berg et al. [21] and Salisbury et al. [20], these findings are not altogether unanticipated and support the notion that study abroad does not automatically produce positive effects.

3.3. Negative Effects. Our findings indicate that study abroad can also foster negative experiences. A minority (two students) of white respondents and none of the respondents of color actually report that studying abroad has negatively affected the likelihood that they will engage with people from different racial backgrounds. Using a sarcastic and overly dismissive tone, one white student responds, "Why does it matter? Studying abroad did not make me suddenly catch yellow fever or make me more 'tolerant' of Asians because I had to live with them." This respondent's use of the terms "yellow fever" (a pejorative phrase used to describe a sexual preference for Asian partners) and "tolerance" (a word which often suggests that a person is simply "putting up" with "others") is telling.

Another response that was unequivocally negative comes from a white student who reveals that she believes study abroad has detrimentally affected the ways she interacts with people from different racial backgrounds. She claims that she is now "quicker to make racist assumptions (about) Hispanic people." She goes on to explain:

I work at a retail store. Before I studied abroad (in Mexico), I made every attempt to speak with customers who did not speak English. I did not want them to feel uncomfortable. Now, I say "I do not speak Spanish" and turn around and get the other person who knows Spanish to assist them. Strangers that I interacted with on a daily basis in Mexico did not give a crap about me and made sure I knew it. Now, I am just returning the favor.

She concludes by stating, "instead of breaking down even more racial barriers, this study abroad trip reconstructed my old ones." Again, this response is not entirely anomalous among US students who study abroad [21]. A variety of factors, including the student's background, location of the program, and the success of on-site facilitation of the learning experience, may lead to this type of reaction. Still, these kinds of responses, particularly given how emotionally charged they appear to be, have the potential to negatively impact their interracial interactions when they return to their home campus, which should be of concern to educators and administrators alike.

3.4. Possible Explanations for These Racial Patterns. To understand further reasons why we see these particular racialized patterns in the reported consequences of study abroad on American students' interracial interactions and openness to racial diversity, we turn back to the quantitative data. One potential explanation is that students of color may be more likely than white students to believe that openness to racial diversity and exposure to difference are integral parts of their educational experiences at the university $[26,27]$.

Table 4 provides empirical support for this argument. Of the eight variables included in our revised version of Pascarella et al's [27] openness to diversity scale, six had statistically significant differences between the responses of students of color and white students. (The two variables that did not have a statistically significant difference between the means of the white students and students of color are "the real value of a college education lies in being introduced to different perspectives" and "The courses I enjoyed the most are those that make me think about things from different perspectives.") Students of color are significantly more likely than their white counterparts to agree with all six questions. For instance, they are more likely to state they enjoy having discussions with people whose racial backgrounds and values are different than theirs. They are also more likely to agree that contact with individuals whose racial background is different than theirs is an essential part of a college education. In many ways, these indicators epitomize the ideal study abroad experience-interacting across difference, challenging one's beliefs and values, and learning about people from different cultures. Thus, these results indicate that students of color may be more likely than white students to embrace the intent of the study abroad experience. 
TABle 4: Mean and Mann-Whitney $U$ test results (the openness to diversity/challenge scale).

\begin{tabular}{|c|c|c|c|}
\hline & $\begin{array}{l}\text { Mean for students of } \\
\text { color (standard } \\
\text { deviation) }\end{array}$ & $\begin{array}{l}\text { Mean for white students } \\
\text { (standard deviation) }\end{array}$ & $U(\mathrm{df})=u$ value, $Z=z$ value, $P$ value \\
\hline $\begin{array}{l}\text { I enjoy having discussions with people } \\
\text { whose racial backgrounds are different } \\
\text { from my own. }\end{array}$ & $7.00(0)$ & $5.80(1.15)$ & $U(60)=52.5, Z=-3.294, P=.001$ \\
\hline $\begin{array}{l}\text { I enjoy talking to people who have } \\
\text { values different from mine because it } \\
\text { helps me understand myself and my } \\
\text { values. }\end{array}$ & $6.86(.378)$ & $5.93(1.12)$ & $U(60)=89.5, Z=-2.432, P=.015$ \\
\hline $\begin{array}{l}\text { Learning about people from different } \\
\text { cultures is a very important part of my } \\
\text { college education. }\end{array}$ & $7.00(0)$ & $6.20(1.06)$ & $U(60)=101.5, Z=-2.276, P=.023$ \\
\hline $\begin{array}{l}\text { I enjoy taking courses that challenge } \\
\text { my beliefs and values. }\end{array}$ & $6.86(.378)$ & $5.86(1.21)$ & $U(60)=85.5, Z=-2.515, P=.012$ \\
\hline $\begin{array}{l}\text { Contact with individuals whose racial } \\
\text { background is different from my own } \\
\text { is an essential part of my education. }\end{array}$ & $6.71(.756)$ & $5.20(1.35)$ & $U(60)=60.0, Z=-3.026, P=.002$ \\
\hline $\begin{array}{l}\text { I enjoy courses that are intellectually } \\
\text { challenging. }\end{array}$ & $7.00(0)$ & $6.32(.987)$ & $U(59)=94.5, Z=-2.412, P=.016$ \\
\hline
\end{tabular}

Note: $\mathrm{df}$ stands for degrees of freedom. The responses to each of the questions were scored on a seven-point scale from $1=$ strongly disagree to $7=$ strongly agree.

However, it may also be the case that students of color indicate greater engagement with and investment in racial diversity simply because the reality of their everyday experience on the predominantly white home campus necessitates regular interracial interactions. Simply being more accustomed to this frame of reference may make students of color more open to racially diverse settings and more willing to consider this terrain of interaction as integral to the college learning environment. It follows that this comfort level would extend to the study abroad experience.

The open-ended responses to the question "Do you think studying abroad was an important part of your liberal arts education" shed additional empirical light on these quantitative findings. Of particular note, $86 \%$ of students of color compared to $27 \%$ of white students point to interacting with people from different cultures as a reason why study abroad is an essential facet of their liberal arts education. For example, one student of color reports, "Studying abroad was an important part of my education since it exposed me to a different culture than the ones to which I have already been exposed."

In their discussion of the importance of studying abroad in their liberal arts education, white students are more likely to talk about study abroad being important for more nebulous reasons-because it "broadened my perspectives and worldviews," "made me more well-rounded," and "exposed me to different lines of thought and learning." In fact, 35\% of white respondents make such references about why they believe study abroad is valuable. One white student explains, "The liberal arts education is about exposing yourself to a wide realm of perspectives and pedagogies and no single experience better allows you to do that than time abroad."

The context of the study abroad session may also play a role in shaping students' interpretation of their study abroad
TABLE 5: Study abroad destinations for respondents.

\begin{tabular}{lcc}
\hline & Students of color & White students \\
\hline Africa & $14 \%$ & $5 \%$ \\
Asia & $0 \%$ & $6 \%$ \\
$\begin{array}{l}\text { The Caribbean } \\
\begin{array}{l}\text { Europe, North America, } \\
\text { Australia, English }\end{array}\end{array}$ & $14 \%$ & $4 \%$ \\
$\begin{array}{l}\text { language } \\
\begin{array}{l}\text { Europe, non-English } \\
\text { native language }\end{array}\end{array}$ & $14 \%$ & $36 \%$ \\
Latin America & $14 \%$ & \\
\hline Total & $43 \%$ & $32 \%$ \\
\hline
\end{tabular}

experience. Table 5 provides information on the geographic locations where respondents studied abroad. Indeed, there are interesting differences in the regions where respondents of color studied compared to white respondents. Students of color are more likely than white students to study in a country outside of Europe, North America, or Australia. In fact, $57 \%$ of students of color studied in Latin America, Asia, or Africa compared to $28 \%$ of white students. Also, $68 \%$ of white students studied in Europe, North America, or Australia compared to $28 \%$ of students of color.

Other findings suggest that when studying abroad, students of color are more likely to be exposed to racial diversity more regularly and across a variety of settings than are white students. Students of color are more likely than white students to live in a "homestay" situation where they reside in the home of a local person or family: $X^{2}(1)=5.707, P<.017$. They are also significantly more likely than white students to report taking courses in a foreign language with other 
nonnative speakers: $X^{2}(1)=9.938, P<.002$. Finally, compared to white respondents, students of color are more likely to report having more frequent daily interactions with people from different racial backgrounds than their own while studying abroad: $U(60)=100.0, z=-2.319, P=.032$.

Our qualitative findings further elucidate the relationship between the location where students studied, frequency of exposure to different racial groups, and openness to diversity upon their return to campus. Students of color acknowledge that these connections existed in their own study abroad experiences. For instance, one student of color reports, "Yes, [my study abroad experiences have affected my openness to racial diversity on campus] because of the diversity that I was surrounded with on a daily basis." In contrast, although white students recognize the importance of the relationship between location, frequency of exposure to different racial groups, and openness to diversity when they return to campus, they also identify the limitations of their study abroad experience. For instance, one student reveals,

I'm sorry, I cannot think of any at the moment, which is telling in itself, is it not? It would be nice if the London program would help students branch out from the upper class, white neighborhood they are comfortably situated in while they are there. More trips to East London, and more opportunities to interact with other London students in general (other than at the pubs) would really help the experience of "different" cultures and racial/ethnic groups.

Another white student explains: "My impressions of diversity on campus seem unrelated to my "European" abroad experience. I have always been open to racial diversity, and I cannot say that going to a mostly white country like the Czech Republic changed that much." It is true that in both of the aforementioned situations, it would have been possible for each of these students to engage with racial diversity, yet the students denote structural limitations to doing so. Also striking is that these students may have been unaware of racial diversity that was part of their lived experience, given the racial heterogeneity present in many study abroad settings.

\section{Discussion and Conclusion}

The current case study offers an exploratory examination of the effects of study abroad on US student engagement with racial diversity - an increasingly important topic and yet one that has received scant scholarly attention in the study abroad literature. This paper also adds to the growing body of scholarship on returnees from study abroad (see [36]) by exploring a small liberal arts college located in the Southern United States.

Our results suggest that there are racialized patterns to students' reported study abroad experiences and their willingness to engage with racial, but, for the most part, not other forms of, diversity once they return from studying abroad. Students of color were more likely than white students to state that they interacted frequently across racial groups while studying abroad. This finding may be due to where they studied and the types of classroom and living experiences they had. In fact, students of color reveal that they were more likely than white students to study abroad in countries where English is not the native language, interact more frequently across racial groups during their study abroad experience, take courses in another language besides English with other native speakers, and participate in a home stay.

We suspect that students of color may be more likely to engage with difference, including racial difference, while studying abroad, in part, because they tend to be more likely than white students to view exposure to diversity (interactions and ideas) as a fundamental part of their liberal arts educational experience. Also, it may be that, given the racial landscape of a predominantly white American university campus and the regularity with which students of color interact across racial groups at their home institution, they are more comfortable and experienced interacting across racial groups in general than are white students.

As a consequence, students of color in our sample are more likely than white students to state that study abroad has positively influenced their racial behaviors and attitudes after their return to their home campus. In particular, students of color more so than white students state that studying abroad has had a positive impact on the frequency with which they interact with people from different racial backgrounds on campus. They also report that studying abroad has increased the likelihood that they will join diversity-related student organizations and seek out a greater diversity of friends based on race. Especially for students of color at a predominantly white institution in the United States, studying abroad in a diverse setting may strengthen their preexisting interest in, and passion for, racial diversity at their university. However, it is also important to keep in mind that a large percentage of all respondents believe that study abroad has had no subsequent effect on the frequency with which they engage with racial diversity. Moreover, a very small group of white students report that study abroad has had a negative impact on their attitudes and behaviors associated with racial interactions.

Although this project extends the literature in substantive ways, there are at least three limitations to note. First, although approximately one-third of the university students who studied abroad completed the online survey, a sample of 62 limited us to using only descriptive, not predictive analyses. Second, our small sample size also unfortunately forced us to aggregate African American, Asian American, Latino, and Native American into one group, "students of color." Lastly, our analyses do not include a pretest so it is impossible to establish a cause and effect relationship between studying abroad and subsequent interracial interaction. Nonetheless, our inclusion of a mixed methods approach to study the impact of study abroad on US students' attitudes and behaviors regarding racial diversity upon their return to campus adds to the prior scholarship in the field.

This case study of a private liberal arts' university in the Southern United States opens up valuable avenues for further systematic and comparative institutional explorations of the racialized processes and consequences of study abroad experiences. Our results may be of particular interest to personnel within the field of study abroad and US college 
educators and administrators who are interested in ways to enhance the opportunities of their students both during and after studying abroad to interact across racial groups. The findings also reveal that university-based study abroad offices may benefit from interrogating the availability of structured opportunities to interact across difference while students study abroad. They may additionally want to consider supporting the development of partnerships across campus to more effectively engage returned study abroad students in articulating and applying what they have learned abroad, particularly as it pertains to experiences and engagement with racial diversity on campus. In this vein, when thinking about diversity, racial diversity should not be subsumed within cultural diversity. Also, if faculty, as teachers and advisors, do not already incorporate discussions of the importance of interracial interactions into their curricula and foster study abroad students' engagement across differences, they may want to consider doing so [2].

Our findings should be of broad interest to administrators and educators. As colleges and universities around the US grapple with issues around study abroad as well as the changing racial, ethnic, and socioeconomic make-up of students, they would be wise to systematically consider the ways that international study may impact the day to day interactions of their students across difference, particularly racial difference, on their home campuses. As our research suggests, US students at the university under study respond differently to study abroad based on racial background. Other institutions should investigate the variety of perceptions and learning experiences that their students are bringing back to the home campus and capitalize on these new understandings to enhance programmatic efforts for future study abroad students.

The goal of increased diversity among study abroad participants continues to be a focus for education abroad professionals and educators in the US. The current study examines whether and how students' experiences while studying abroad affect their openness towards engaging with racial diversity. While one may not expect to see similar results from this study replicated outside the US, it may be reasonable to assume that students' behaviors and attitudes towards other types of difference may indeed exhibit similar patterns of development. This avenue of inquiry may prove fruitful to scholars around the world.

\section{Conflict of Interests}

The authors declare that there is no conflict of interests regarding the publication of this paper.

\section{Acknowledgments}

This project was carried out with funds from Associated Colleges of the South Faculty Mellon Grant awarded to Maria R. Lowe, Reginald A. Byron, and Susan Mennicke. The authors would like to thank anonymous reviewers for their constructive feedback.

\section{References}

[1] K. Fischer, "Colleges are urged to try new approaches to diversify study abroad," The Chronicle of Higher Education, 2012, http://chronicle.com/article/Colleges-Are-Urged-to-TryNew/130908/.

[2] J. M. Brux and B. Fry, "Multicultural students in study abroad: their interests, their issues, and their constraints," Journal of Studies in International Education, vol. 14, no. 5, pp. 508-527, 2010.

[3] U.S. Department of Education, National Center for Education Statistics, and Integrated Postsecondary Education Data System (IPEDS), Characteristics of Postsecondary Students, The Condition of Education, 2014, http://nces.ed.gov/programs/coe/indicator_csb.asp.

[4] Institute of International Education, Open Doors, 2011. U.S. Study Abroad: Student Profile, 2013, http://www.iie.org/Research-and-Publications/Open-Doors/Data/US-Study-Abroad/ Student-Profile/2000-13.

[5] J. Simon and J. W. Ainsworth, "Race and socioeconomic status differences in study abroad participation: the role of habitus, social networks, and cultural capital," ISRN Education, vol. 2012, Article ID 413896, 21 pages, 2012.

[6] M. H. Salisbury, M. B. Paulsen, and E. T. Pascarella, "Why do all the study abroad students look alike? Applying an integrated student choice model to explore differences in the factors that influence white and minority students' intent to study abroad," Research in Higher Education, vol. 52, no. 2, pp. 123-150, 2011.

[7] S. Rose and J. Bylander, "Border crossings: engaging students in diversity work and intergroup relations," Innovative Higher Education, vol. 31, no. 5, pp. 251-264, 2007.

[8] W. Hoffa and S. de Paul, "A history of study abroad: 1965-present," Frontiers: The Interdisciplinary Journal of Study Abroad, vol. 21, Fall, 2011.

[9] E. M. Norris and J. Gillespie, "How study abroad shapes global careers: evidence from the United States," Journal of Studies in International Education, vol. 13, no. 3, pp. 382-397, 2009.

[10] K. Hendershot and J. Sperandio, "Study abroad and development of global citizen identity and cosmopolitan ideals in undergraduates," Current Issues in Comparative Education, vol. 12, pp. 45-55, 2009.

[11] R. M. Paige, G. Fry, E. M. Stallman, J. Josic, and J. Jon, Study Abroad for Global Engagement: The Long-Term Impact of Mobility Experiences, AFS, New York, NY, USA, 2009.

[12] I. Bohrer, "Study abroad increases professional job prospects in times of crisis," Transitions Abroad, July 2010, http://www. transitionsabroad.com/listings/study/articles/study-abroad-increases-professional-job-prospects.shtml

[13] J. McKeown, The First Time Effect: The Impact of Study Abroad on College Student Intellectual Development, SUNY Press, Albany, NY, USA, 2009.

[14] L. A. Braskamp, D. C. Braskamp, and K. Merrill, "Assessing progress in global learning and development of students with education abroad experiences," Frontiers: The Interdisciplinary Journal of Study Abroad, vol. 18, pp. 101-118, 2009.

[15] R. Sutton and D. Rubin, "The GLOSSARI project: initial findings from a system-wide research initiative on study abroad learning outcomes," Frontiers: The Interdisciplinary Journal of Study Abroad, vol. 10, pp. 65-82, 2004.

[16] R. Slimbach, Becoming World Wise: A Guide to Global Learning, Stylus, Sterling, Va, USA, 2010. 
[17] P. Gardner, L. Gross, and I. Steglitz, "Unpacking your study abroad experience: Critical reflection for workplace competencies," College Employment Research Institute, vol. 1, no. 1, pp. 110, 2008.

[18] P. J. Pedersen, "Assessing intercultural effectiveness outcomes in a year-long study abroad program," International Journal of Intercultural Relations, vol. 34, no. 1, pp. 70-80, 2010.

[19] M. Vande Berg, R. M. Paige, and K. H. Lou, Eds., Student Learning Abroad: What Our Students Are Learning, What They're Not, and What We Can Do about It, Stylus Publishing, Sterling, Va, USA, 2012.

[20] M. H. Salisbury, B. P. An, and E. T. Pascarella, "The effect of study abroad on intercultural competence among undergraduate college students," Journal of Student Affairs Research and Practice, vol. 50, no. 1, pp. 1-20, 2013.

[21] M. V. Berg, R. M. Paige, and J. Connor-Linton, "The Georgetown consortium project: interventions for student learning abroad," Frontiers: The Interdisciplinary Journal of Study Abroad, vol. 17, pp. 1-75, 2009.

[22] M. Goode, "The role of faculty study abroad directors: a case study," Frontiers: The Interdisciplinary Journal of Study Abroad, vol. 15, pp. 149-172, 2008.

[23] M. McCallon and B. Holmes, Faculty-Led 360: Guide to Successful Study Abroad, Agapy, LLC Publishing, Charleston, Ill, USA, 2010.

[24] R. Lewin, The Handbook of Practice and Research in Study Abroad: Higher Education and the Quest for Global Citizenship, Routledge, New York, NY, USA, 2009.

[25] A. W. Chickering and I. Reisser, Education and Identity, JosseyBass, San Francisco, Calif, USA, 2nd edition, 1993.

[26] T. I. Wortman, Psychosocial effects of studying abroad: openness to diversity [Ph.D. thesis], Pennsylvania State University, 2002.

[27] E. T. Pascarella, M. Edison, A. Nora, L. S. Hagedorn, and P. T. Terenzini, "Influences on students' openness to diversity and challenge in the first year of college," Journal of Higher Education, vol. 67, no. 2, pp. 174-195, 1996.

[28] B. Ismail, M. Morgan, and K. Hayes, "Effect of short study abroad course on student openness to diversity," Journal of Food Science Education, vol. 1, pp. 15-18, 2006.

[29] S. R. Harper and S. Hurtado, "Nine themes in campus racial climates and implications for institutional transformation," New Directions for Student Services, vol. 2007, no. 120, pp. 7-24, 2007.

[30] A. Lewis, M. Chesler, and T. Forman, "The impact of "colorblind" ideologies on students of color: intergroup relations at a predominantly white university," The Journal of Negro Education, vol. 69, no. 5, pp. 74-91, 2000.

[31] K. McClelland and C. Auster, "Public platitudes and hidden treasures: racial climates at predominantly white liberal arts colleges," The Journal of Higher Education, vol. 61, no. 6, pp. 601642, 1990.

[32] K. D. McKinney, "I feel "whiteness" when I hear people blaming whites: whiteness as cultural victimization," Race and Society, vol. 6, no. 1, pp. 39-55, 2003.

[33] S. R. Rankin and R. D. Reason, "Differing perceptions: how students of color and white students perceive campus climate for underrepresented groups," Journal of College Student Development, vol. 46, no. 1, pp. 43-61, 2005.

[34] Y. Suarez-Balcazar, L. Orellana-Damacela, N. Portillo, J. M. Rowan, and C. Andrews-Guillen, "Experiences of differential treatment among college students of color," Journal of Higher Education, vol. 74, no. 4, pp. 428-444, 2003.
[35] D. Means, "The racial wall: an evaluation of social interaction between whites and blacks on a predominantly white university campus," South Carolina College Personnel Association, Palmetto Practitioner Issues in Student Affairs, 2006, http:// www.sccpaweb.org/palmettopractitioner/2006/\#anchor_36.

[36] D. Haines, “"More aware of everything”: exploring the returnee experience in American higher education," Journal of Studies in International Education, vol. 17, no. 1, pp. 19-38, 2013.

[37] S. Hurtado, "The campus racial climate: contexts of conflict," The Journal of Higher Education, vol. 63, no. 5, pp. 539-569, 1992.

[38] E. B. Penn and J. Tanner, "Black students and international education: an assessment," Journal of Black Studies, vol. 40, no. 2, pp. 266-282, 2009.

[39] E. McCrum-Gardner, "Which is the correct statistical test to use?" British Journal of Oral and Maxillofacial Surgery, vol. 46, no. 1, pp. 38-41, 2008.

[40] V. Braun and V. Clarke, "Using thematic analysis in psychology," Qualitative Research in Psychology, vol. 3, no. 2, pp. 77-101, 2006. 

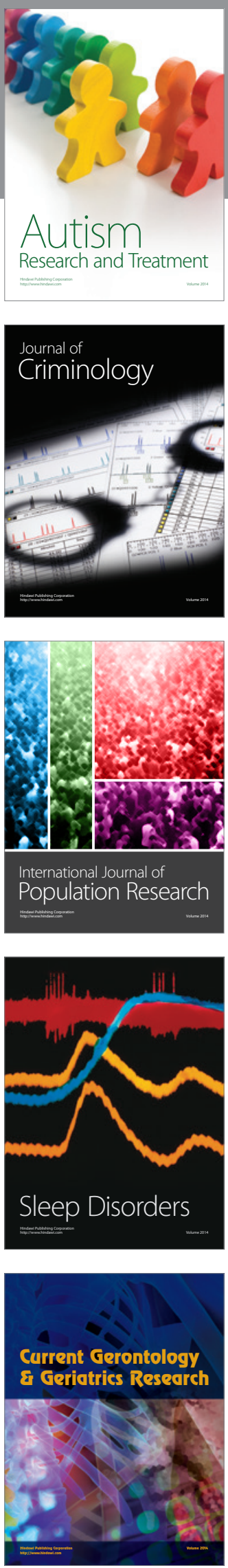
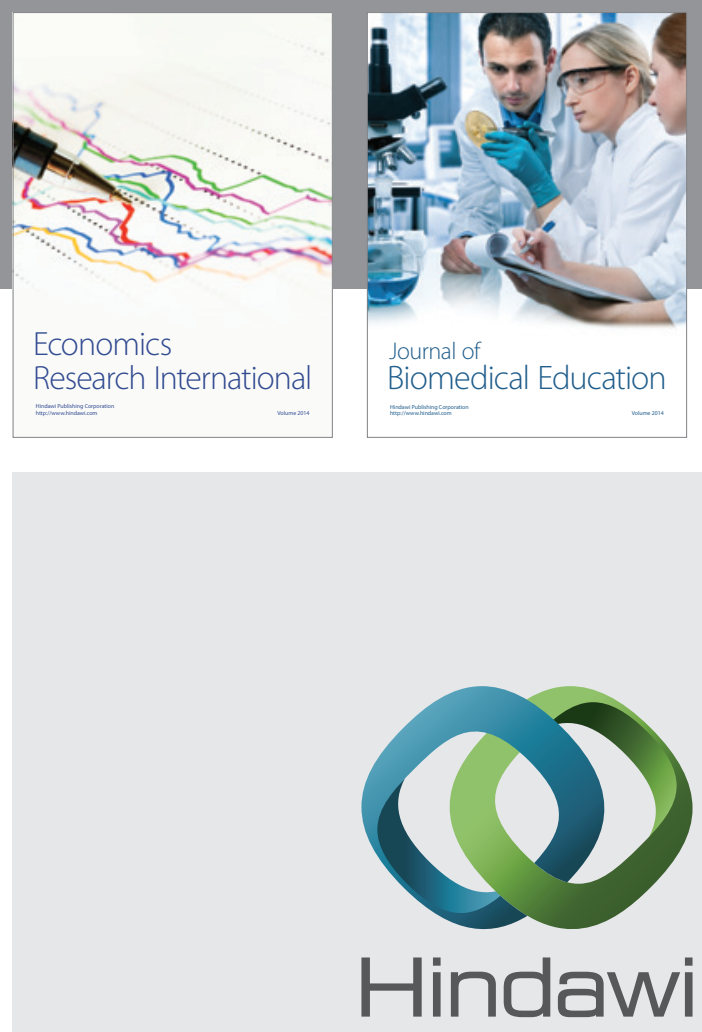

Submit your manuscripts at

http://www.hindawi.com
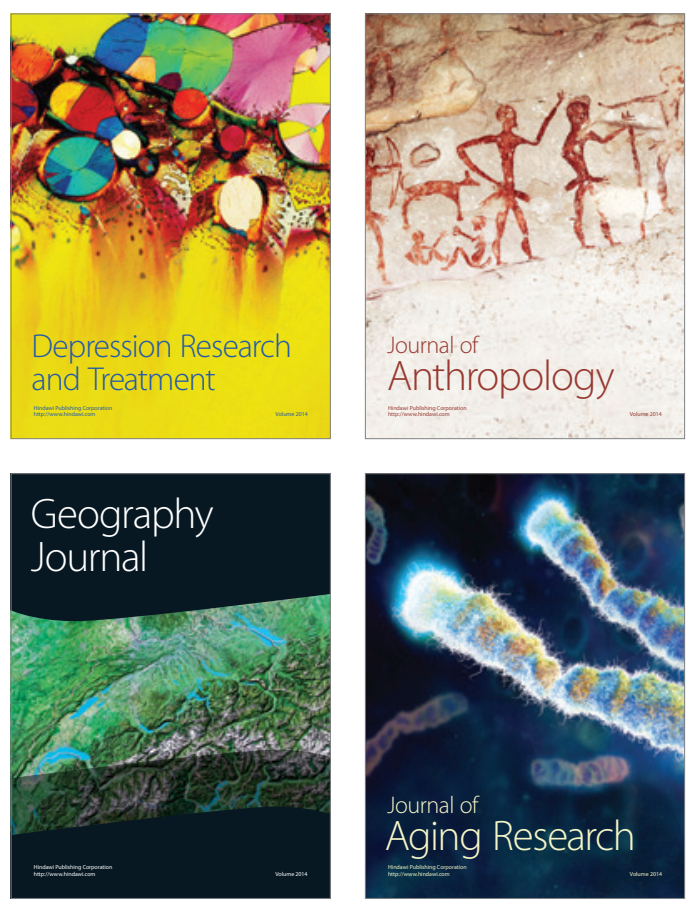
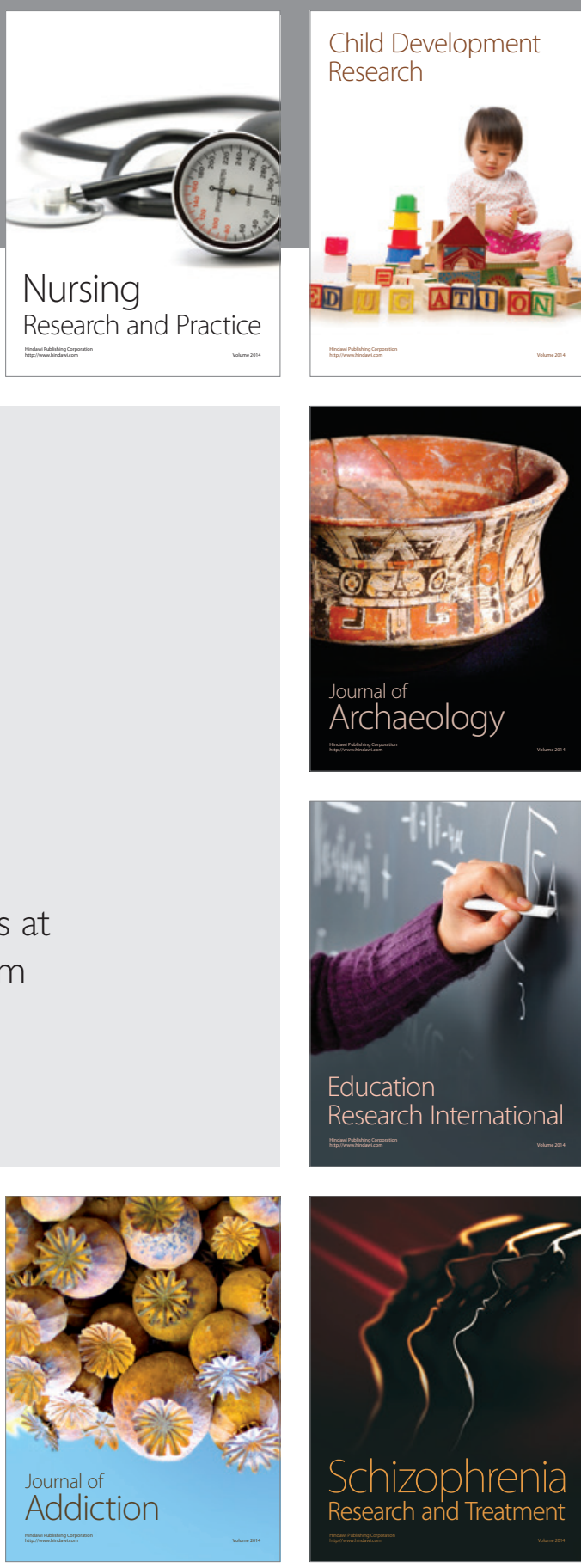

(D)
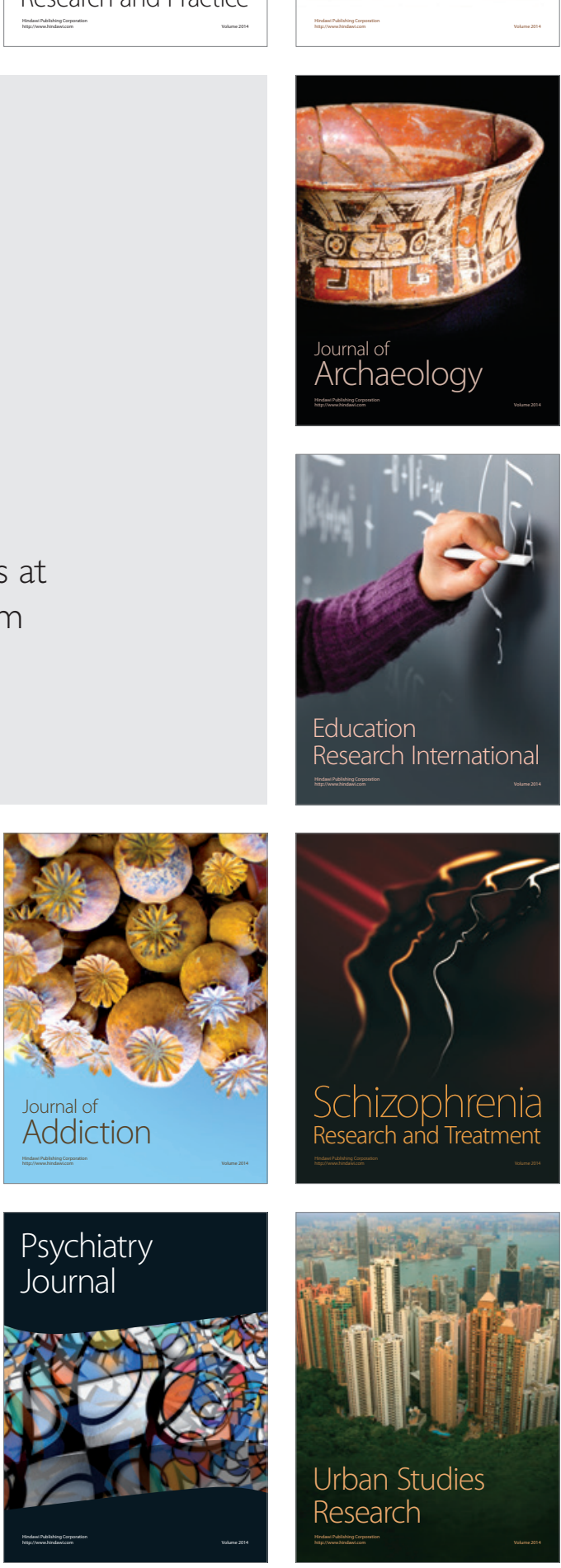